\title{
High thoracic disc prolapse in a rugby player: the first reported case
}

\author{
P. R. Davies MB BS FRCS and G. Kaar MB BS BSc PhD FRCS* \\ Department of Neurosurgery, Radcliffe Infirmary, Oxford and *Department of Neurosurgery, Aberdeen Royal \\ Infirmary, UK
}

\begin{abstract}
Traumatic disc prolapse in the thoracic region is not common, and is rare above the T3 level. A case of a T1-T2 disc prolapse as a result of rugby injury is described.
\end{abstract}

Keywords: Thoracic disc prolapse, rugby player

Only $1 \%$ of all disc prolapses occur at the thoracic level ${ }^{1}$. The majority occur in the lower thoracic region with only $4 \%$ found above T3. Trauma accounts for $25 \%$ of such reported injuries ${ }^{2}$. We now report such a case in a rugby football player.

\section{Case report}

A 32-year-old, previously fit and healthy man, presented with a 2-day history of interscapular pain with numbness and weakness in both legs. He had been playing as a tight head prop-forward in a rugby match when he experienced the sudden onset of severe and unusual interscapular pain on engaging in a scrummage. Immediately after the match he began to suffer numbness along the lateral aspect of the left thigh and calf. He was seen in the casualty department of his local hospital where a neurological examination was entirely normal, and radiographic examination of both legs revealed no abnormality.

Two days later he presented again with increasing weakness of both legs, numbness to the level of his chest and difficulty in micturition. Clinical examination revealed marked sensory impairment of all modalities to the level of T4 and a marked spastic paraparesis with hypereflexia and bilateral extensor plantar responses. He was only just able to walk unaided and had a spastic gait. Examination of the abdomen revealed a distended, non-tender bladder.

Myelography and computerized tomography revealed an almost complete obstruction of the spinal canal at the level of the T1-T2 disc space due to compression of the cord by a mass lying anteriorly (Figures 1 and 2). Anterolateral exploration via a costotransversectomy was carried out which revealed

Address for correspondence: P. R. Davies, Department of Neurosurgery, Radcliffe Infirmary, Oxford, UK

(C) 1993 Butterworth-Heinemann Ltd

0306-3674/93/030177-02 a large sequestered prolapse of the T1-T2 intervertebral disc. This was satisfactorily removed.

After operation, there was rapid recovery of power and sensation. At $48 \mathrm{~h}$, the patient was fully mobile with normal bladder control. At outpatient review, there was no residual neurological deficit.

\section{Discussion}

Although intervertebral disc prolapse is not uncommon in the thoracic region, it is commonest at lower thoracic levels and is rarely described above the T3 level. In the case now reported, the unusual feature is the height at which the prolapse occurred. The history was highly suggestive of prolapse with the alternatives of haematoma or neoplasm as possible causes of compression.

It is likely that the prolapse in this instance was directly related to the physical stress exerted on the cervical and upper thoracic spine in the engagement phase of the two front rows of forwards in the scrummage. This player was the tight head prop-

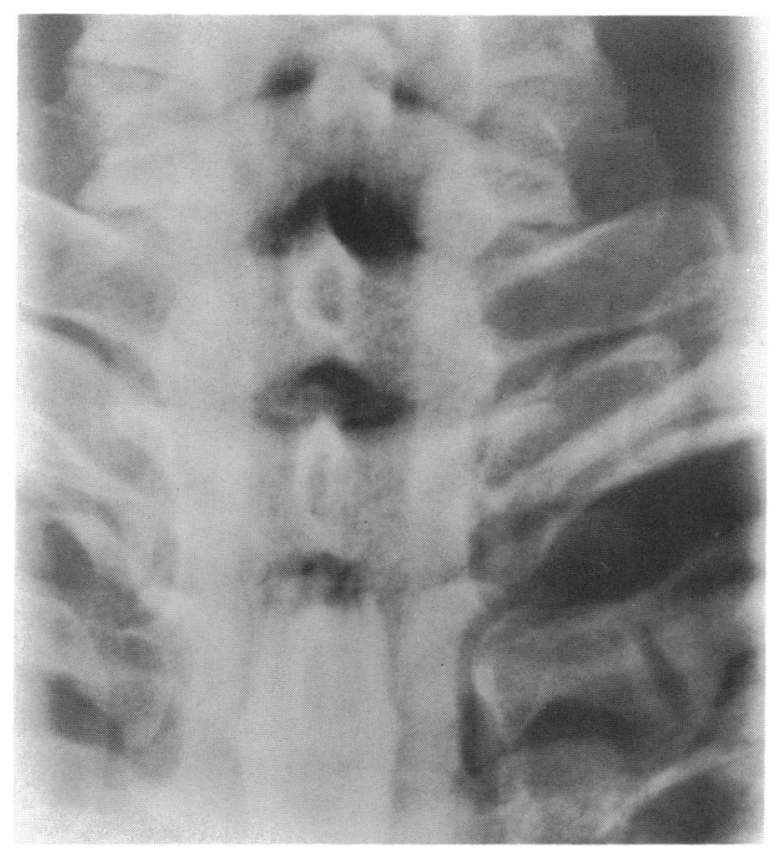

Figure 1. Myelography of spine reveals obstruction of spinal canal at level of T1-T2 disc space 


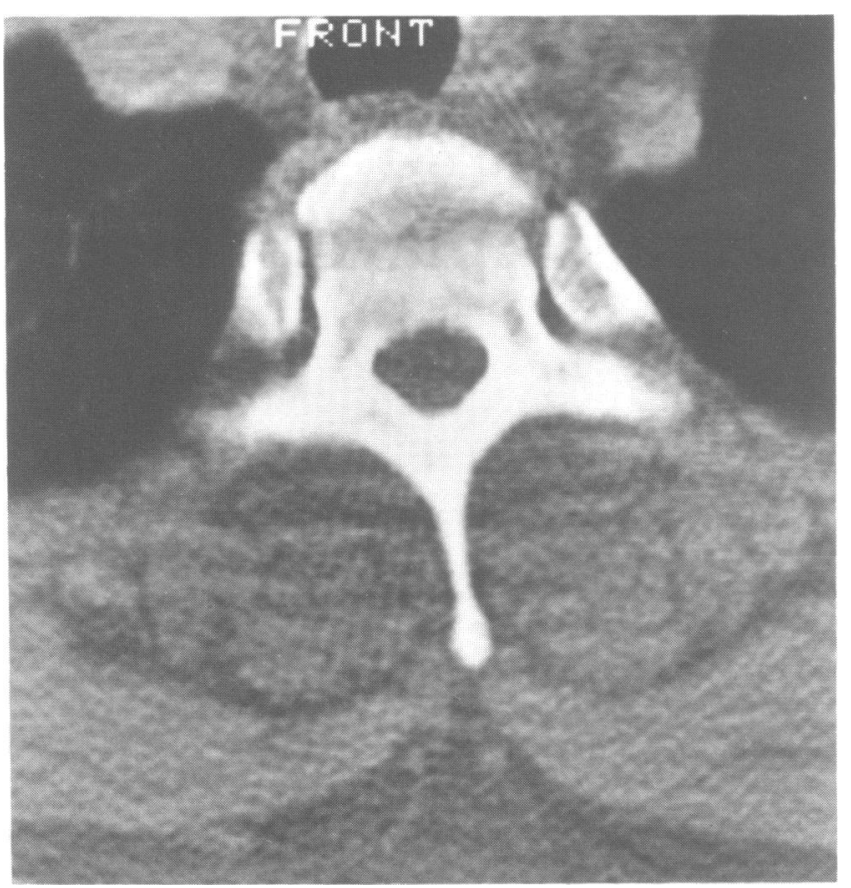

Figure 2. Computerized tomography reveals compression of spinal cord by anterior mass overlying $\mathrm{T} 1-\mathrm{T} 2$ disc space

forward and had his neck in the vice formed by the heads of the opposing hooker and loose head prop-forward )Figure 3). Only the hooker and tight head prop-forward are subject to similar stress having the maximum force (the combined effort and weight of eight opposing and rear thrust of five supporting forwards) exerted through the spine. The angulation of the cervical spine in the front row engagement is such as to lay more direct stress on the C7-T3 region of the spine. Supporting second row forwards, although similarly engaged are able to maintain a straighter spinal position with little or no angulation.

Spinal injuries only form a small but important fraction of the total injuries suffered in rugby football. The cervical or lumbar spine is usually involved ${ }^{3}$. Fractures and dislocations of the cervical spine may result in quadriplegia ${ }^{4}$. Of 30 cases of cervical disc herniation in athletes, one patient presented with an acute myelopathy. Interestingly, this was a rugby player who developed a soft central prolapse at $\mathrm{C} 6-\mathrm{C}^{5}$.

Thoracic disc prolapse has not been previously described in a rugby player and although a rare event, it is nevertheless a serious but retrievable situation. Early diagnosis and decompression are essential if permanent disability is to be avoided.

\section{Acknowledgement}

We would like to thank Mr P. J. Teddy, Consultant Neurosurgeon, for permission to report this case.

\section{References}

1 Cason J, Gumpert J, Jefferson A. Diagnosis and treatment of thoracic intervertebral disc protrusion. I Neurol Neurosurg Psychiatry 1971; 34: 68-77.

2 Arce CA, Dorhmann GJ. Thoracic disc herniation, improved diagnosis with computerised tomographic scanning and review of the literature. Surg Neurol 1985; 23: 356-61.

3 Michaeli LJ, Riseborough EM. The incidence of injuries in rugby football. J Sports Med; 2: 2 .

4 Torg J. Athletic Injuries to the Head, Neck and Face. Philadelphia: Lea and Febiger, 1982: 189-209.

5 Kumano K, Umayama T. Cervical injuries in the athlete. Arch Orthop Trauma Surg 1986; 105: 223-6.

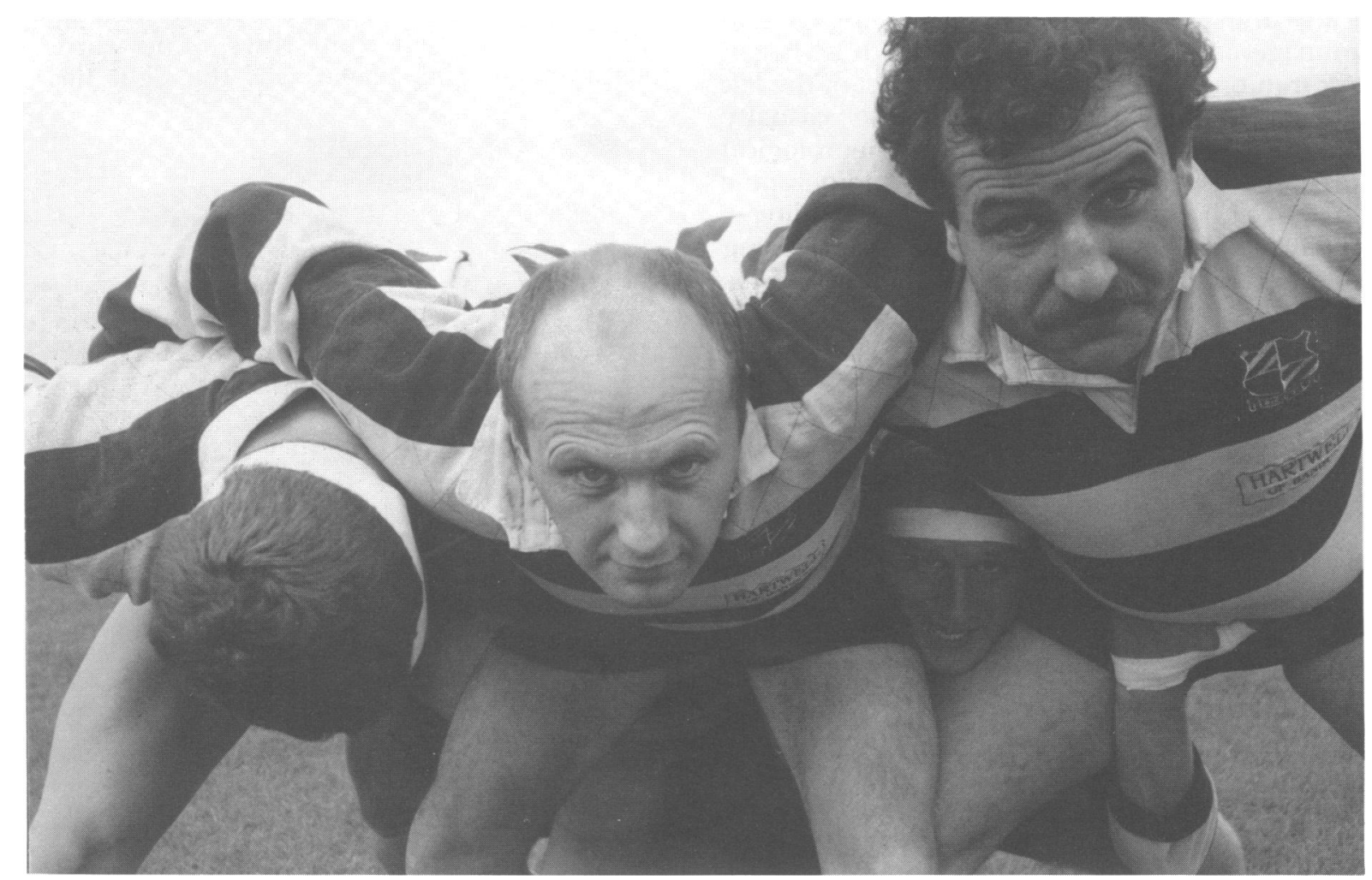

Figure 3. Rugby scrummage 